\title{
Silicon Nitride as a Reinforcement for Aluminium Metal Matrix Composites to Enhance Microstructural, Mechanical and Tribological Behavior
}

\author{
Ranjeet Kumar Arya, Amit Telang
}

\begin{abstract}
In recent years, aluminium and its hybrid composites receiving more attention due to its excellent property combinations like improved mechanical properties, better wear and high corrosion resistance, ease to process and probably reduced production cost etc.. Composite is made of two phases one is matrix and another one is reinforcement. The performance of composite highly depends on some key factors that decide overall performance and they are properties of constituent phases, reinforcement size, reinforcement distribution in the matrix and their interfacial interaction. Particle reinforced metal matrix composites (particulate metal matrix composites- PMMCs) are becoming more popular due to their low cost, easy to process and compatible to conventional processing techniques. Also they give isotropic properties. The most commonly used reinforcements are carbides, oxides and nitrides. A lot of research has taken place including carbide and oxide as a reinforcement particles for aluminum matrix composites (AMCs) and hybrid aluminium matrix composites (HAMCs) while there is a bit research lag in use of nitride as a reinforcement for development of AMCs and HAMCs. Recent competitive market demands the material having better combination of properties, cost effectiveness and eco-friendly nature. Present article focused on to study the microstructural features, physical properties, mechanical and tribological behavior of aluminium matrix composites when reinforced with silicon nitride particles (Si3N4). Potential area of applications has also been suggested on the basis of literature data. In this review a comprehensive study has done for current scientific development carried out in Al based Si3N4 composites as well as its future scope has also been discussed.
\end{abstract}

Keywords: Particle reinforced metal matrix composites (PMMCs), silicon nitride (Si3N4) particles, aluminium matrix composites, hybrid aluminium matrix composites.

\section{INTRODUCTION}

Metal matrix composites (MMCs) are growing continuously. In this, metal is used as matrix while ceramic or other organic compounds are taken as reinforcement. Auminium (Al), magnesium (Mg) and titanium(Ti) are light in weight

Revised Manuscript Received on February 05, 2020.

* Correspondence Author

Ranjeet Kumar Arya*, Department of Mechanical Engineering, M.A.N.I.T, Bhopal, India. Email: jeetarya2009@gmail.com

Dr. Amit Telang, Department of Mechanical Engineering, M.A.N.I.T, Bhopal, India. Email: atelang7@rediffmail.com

(C) The Authors. Published by Blue Eyes Intelligence Engineering and Sciences Publication (BEIESP). This is an open access article under the CC BY-NC-ND license (http://creativecommons.org/licenses/by-nc-nd/4.0/) and due to this reason they are widely used as metallic matrix material [1-3]. Ceramic reinforced metal matrix composites are found to be very prominent materials for the purpose of structural applications due to its excellent property combinations like ductility, toughness, high strength, high modulus; which is the result of interaction of its constituting phases i.e. metal matrix and ceramic reinforcement [4-5]. Type of reinforcement and fabrication method of the composite play an important role to influence the physical and mechanical properties of the composites [6]. Shape of the reinforcement may be fiber, particulate or whiskers type; fiber and particulates are most commonly used shape of the reinforcement. A proper selection of matrix \& reinforcement and shape of the reinforcement is highly desirable for property improvement of the composite [7-9]. In recent years, aluminium and its alloys are most widely used non-ferrous metals and getting more popularity due to its high strength to weight ratio, easy to fabricate, and low production cost [10,11,12]. Aluminum metal matrix composites (AMMCs) reinforced with ceramic particles are simple \& easy to process and also have the potential to give tailored property combinations [13]. These tailored property combinations make composites more promising for automobiles and aerospace applications [14-16]. High hardness and low coefficient of thermal expansion are some of common properties of ceramic reinforcements which give a rise to direct and indirect strengthening of final aluminium composite $[17,18,19]$. Automobiles components that works under friction and temperature environment are manufactured by hard ceramic composites and for this SiC, B4C, Al2O3, Si3N4 are widely used to develop AMMCs [20-22]. From the literature it is found that the nitride ceramic reinforcement (AIN, Si3N4) are propitious materials for the development AMMCs as they have high heat conductivity, high specific modulus, low density and stability at high temperature. Hybrid metal matrix composite (HMMC) is the class of composite in which metal matrix is reinforced by two or more reinforcements [22-24]. Now a days concept of HAMCs is in lime light because they offer flexibility in terms of selection of reinforcements to obtain the desired properties of final composite and more reliable to the desired expectations $[25,26]$. Discontinuous metal matrix composites may be fabricated by a no of manufacturing processes; among them stir casting considered as important one and also used commercially. It is a liquid metallurgical route of manufacturing of composites. 
In this method reinforcement is introduced in the molten metal and to achieve uniform dispersion in melt mechanical stirrer is used. It is inexpensive, simple, flexible and easily applicable for mass production which make it advantageous [27]. Its production capacity and cost effectiveness give it more attention [28]. Some factors are being considered with the use of stir casting for developing aluminium metal matrix composites, this includes: obtaining homogeneous distribution of hard ceramic or reinforcing particles within the matrix, establishing wettability between matrix and reinforcement phase to get good intermetallic bond and minimizing the porosity in MMCs. These factors can be achieved by taking proper position of stirrer, its geometry, furnace temperature according to properties of used matrix and reinforcements $[29,30]$.

The present article is focused on to review the outcome when Si3N4 is used as a reinforcement to develop the AMMCs, what is its feasibility with aluminium matrix and property enhancement after its introduction etc. It is found from the literature the Silicon nitride (Si3N4) has excellent mechanical and wear properties along with high thermal shock resistance, good thermal conductivity hence as a reinforcement it is feasible to use for fabricating AMMCs [31]. From the different studies it also found that $\mathrm{Al} / \mathrm{Si} 3 \mathrm{~N} 4$ AMCs offer high strength to weight ratio compared to that of unreinforced alloy [32]. Silicon nitride based composites have the potential to be used as a advanced structural material since it offers excellent property combinations for example high mechanical strength, good resistance to wear and corrosion, high chemical and thermal stability at normal ambient and elevated temperature [33].Low density, high melting point, good wear resistance and toughness make this non-oxides ceramic attractive to use for various applications e.g. to use as bearing material [34-37]. Manufacturing of Heat exchangers, bearings, engine components, turbine blades are some of the areas where Si3N4 are used prominently [38].

This review will comprehensively cover physical, mechanical, microstructural and tribological properties of AA/Si3N4 composites and also lights on its future perspectives.

\section{LITERATURE REVIEW}

\section{A. Physical Properties : Density \& Porosity}

Pardeep et al. [30] investigated the effect of change of wt\% composition of Si3N4 on density and porosity of final composite material (AA6082/Si3N4) and found very small effect of its presence on density as initially (alloy AA6068) the density was $2.69 \mathrm{gm} / \mathrm{cm} 3$ with $0 \mathrm{wt} \% \mathrm{Si} 3 \mathrm{~N} 4$ while it is $2.75 \mathrm{gm} / \mathrm{cm} 3$ with $12 \mathrm{wt} \% \mathrm{Si} 3 \mathrm{~N} 4$ as shown in table. 1. High density of Si3N4 $(3.44 \mathrm{gm} / \mathrm{cm} 3)$ may be the reason of this density rise.Table. 1 also shows the porosity rise with the

\begin{tabular}{|ccc|}
\hline \multicolumn{3}{|c|}{ Table.1 : Density \& porosity variation with respect to } \\
change in wt \% of Si3N4 particle [30]
\end{tabular}

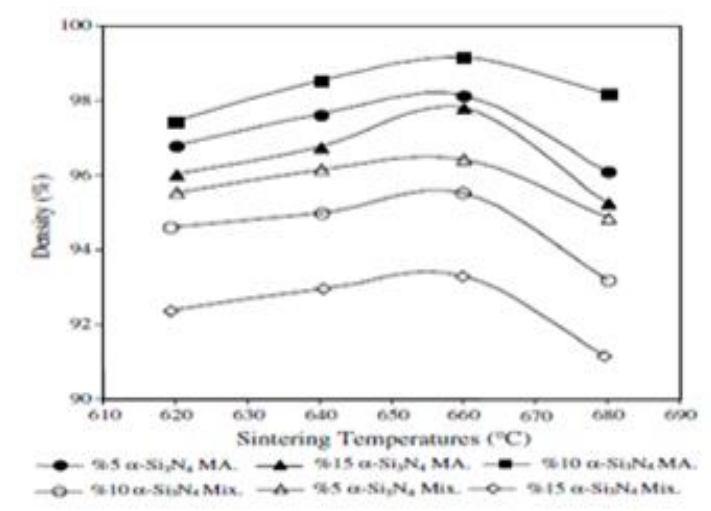

Fig.1: Sintering temperature effect on different sample density [39]

increment of Si3N4wt\%. Presence of impurities in both phases may be the reason of this porosity rise. [30].Arik [39] had reported that the density of different sample (mechanically \& ball milled samples $\mathrm{Al} / \mathrm{Si} 3 \mathrm{~N} 4$ of 5,10,15 wt $\%$ ) goes up with increasing the sintering temperature and achieved its maximum value as $660^{\circ} \mathrm{C}$ sintering temperature has reached and then goes down as displayed in fig. 1 . The highest value was obtained for $10 \mathrm{wt} \%$ of Si3N4. Consistent spreading of the reinforcement is responsible for this density rise. Furthermore, Ramesh et al. [40] examined that the forging improves the porosity of AA6061 which may be due to the elimination of minor flaws that comes during the casting of the AA6061 alloy and AA6061/Si3N4 composite. The porosity variation is shown in Table.2, that shows there is a rise in porosity as wt\% increases. Sharma et. al [41] had proposed from experiment that the density of the Al6082/(ball-milled Si3N4-Gr) hybrid composite increases as the $\mathrm{wt} \%$ of reinforcements increase. The density increased by $10.33 \%$; the reason behind this rise is the high density of reinforced material. Similarly the apparent porosity also get increased with rise in wt\%; it increase by 0.37 to $1.64 \%$ which may be due to impurities in $\mathrm{Al}$ and Si3N4/Gr. According to Bai et al. [42], density is poor with Al2O3/15 and $20 \mathrm{wt} \%$ of the Si3N4 composite due to presence of several number of pores at grain boundaries but it get increased and offer high density with 25wt\% Si3N4.

Shalby et al. [43] performed the experiment on A359/Sic-Si3N4 and found that the density increased as the $\mathrm{wt} \%$ of reinforcement increased; it is due to high density of reinforcing material. It is also reported that the density increased for squeezed cast composite as compare to as cast composite which may be attributed to application of pressure during squeeze casting process. After squeezing process, Porosity get decreased. Senel et al. 
[44] observed that composite (Al-Si3N4) formed via Powder metallurgy (P/M route) route give an increase in apparent density from 2.51 to $2.55 \mathrm{gm} / \mathrm{cm} 3$, and concluded that with the addition of Si3N4 even via P/M route, the density get increased and it increases up to $9 \mathrm{wt} \%$ of Si3N4 and on further increment of Si3N4 density get decreased, may be due to agglomeration.

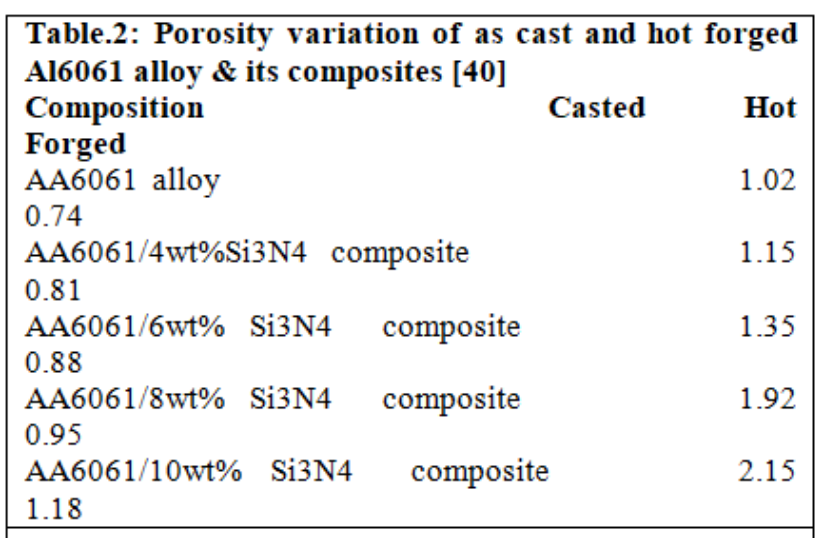

\section{B. Microstructural features}

Attainment of uniform distribution of reinforcement in the matrix and avoiding the chances of agglomeration is the primary objective for the development of material. This can be verified by microstructural analysis with the help of optical microscopy, SEM or TEM analysis.

$\mathrm{XIU}$ et al. [45] fabricated (Si3N4)p/Al composite by pressure infiltration method using three volume fraction of Si3N4 (45\%, 50\% and 55\%) . For microstructural analysis optical micrographs and SEM images have taken. It revealed the well infiltrated composites (Al/Si3N4) with uniform particle distribution and no apparent porosity or significant casting defects. Also observed high dislocation density around Si3N4 particles in Al matrix. J. Fayomi et al. [46] developed AA8011/ZrB2-Si3N4 hybrid metal matrix composites by double steps stir casting process using reinforcement as $0,5,10,15 \& 20$ wt \% (half \& equal of each reinforcement). Optical micrograph revealed uniform dispersion for last three composition (i.e. 10, 15, $20 \mathrm{wt} \%$ ) while composite with

$5 w t \%$ reinforcement possess small clustering, which may be due to stirring process. It is also found that there was a strong intermetallic bonding and excellent wettability along with uniform dispersion for last three composition which may be attributed to the process parameters used during double step stir casting $[47,48]$. SEM images also detect the same result with no small clustering and no visible micro-cracks.

fig. 2 shows SEM image of pure Si3N4 ceramic particle done by Pardeep Sharma et al. [49]. They characterized the cast

AA6082 alloy with 0 wt\% of Si3N4 and AMCs for all composition by optical microscope. Optical micrograph image as in fig. 3 (a) reveals the microstructure of cast AA6082 that contains solid solution of $\mathrm{Al}$ with inter-dendritic system of Al-Si eutectic while composite for

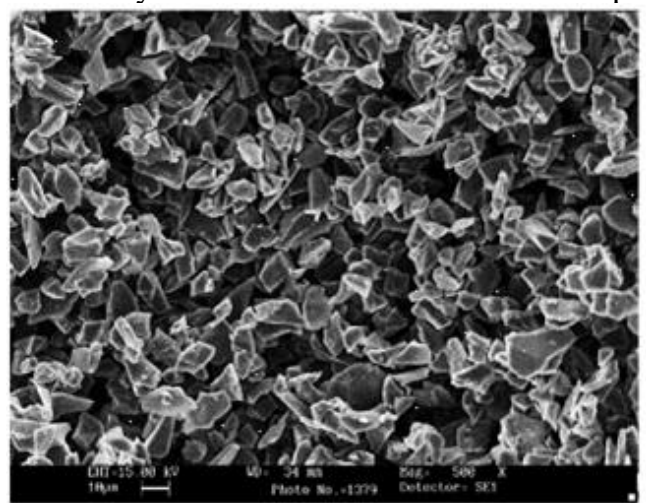

Fig.2: SEM image for Pure Si3N4 Powder [49]

all compositions indicates the presence of Si3N4 reinforcement particles in the matrix along with $\mathrm{Mg} 2 \mathrm{Si}$ precipitates as in fig.3(b-e, optical micrograph images), here magnesium and silicon are main constituent of matrix (AA6082). Fig. 4(a) represents SEM image of casted
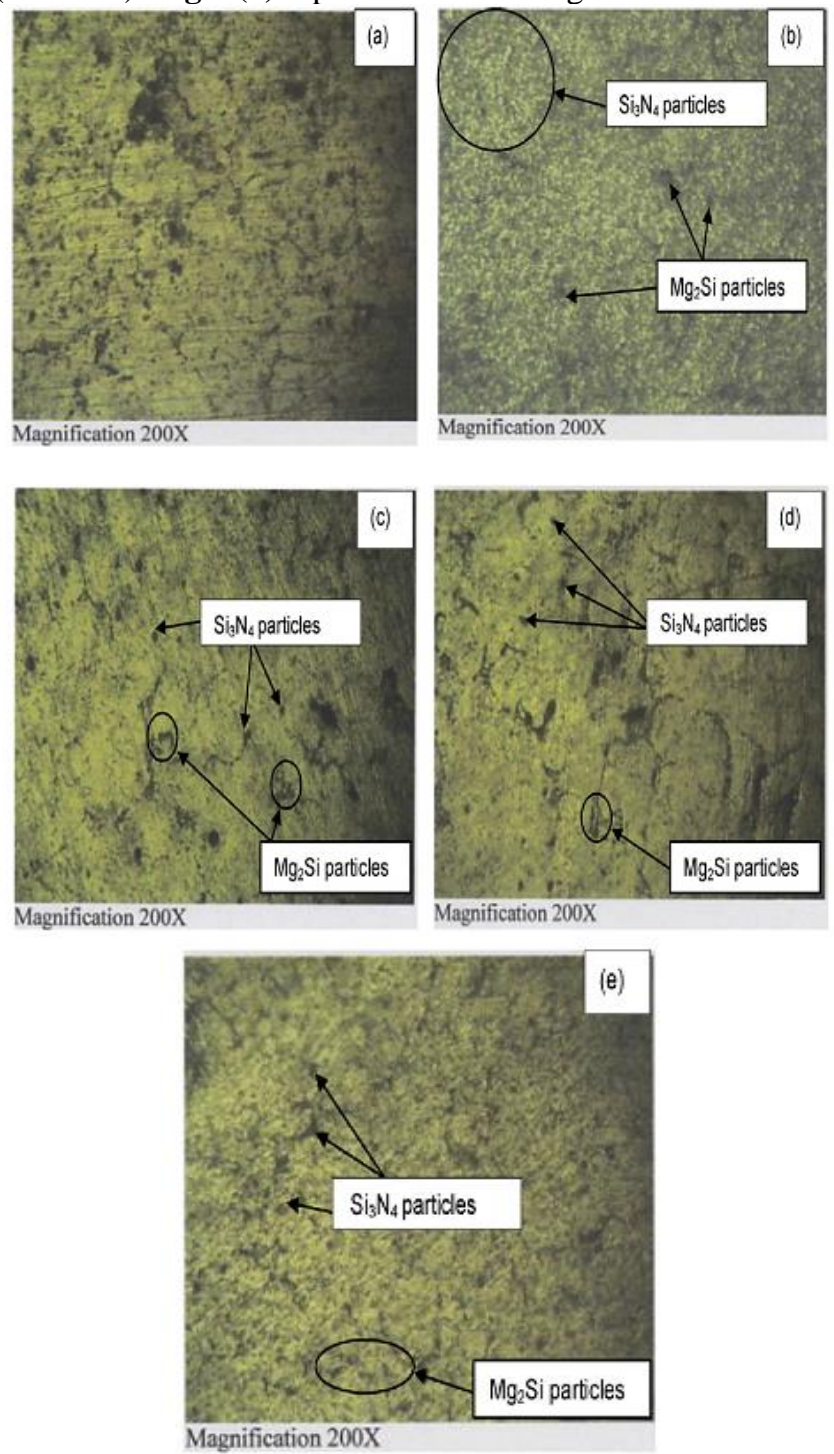

Fig.3. "Optical micrographs of cast AA6082-Si3N4 AMCs: (a) 0\% Si3N4, (b) 3\% Si3N4, (c) 6\% Si3N4, (d) 9\% Si3N4 and (e) 12\% Si3N4" [49].

Published By:

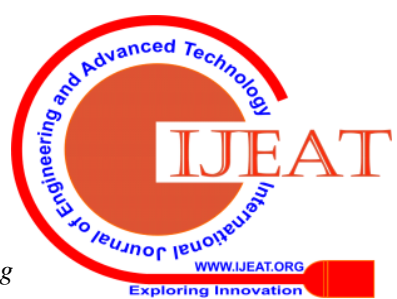



and Tribological Behavior

AA6082 while Fig. 4(b)-(e) display the SEM images of AMCs for different wt\% of Si3N4, it reveals he presence of Si3N4 particulates in matrix. Some places occurred with clustering of Si3N4 particles which may be due to density difference between Si3N4 particles $(3.44 \mathrm{gm} / \mathrm{cm} 3)$ and aluminium (2.7 gm/cm3). SEM images in Fig. 4(f)-(g) fabricated aluminium composite by different wt\% (5, 10 and 15\%) of Si3N4 in AA 6061 matrix via powder metallurgy route. The optical micrographs reveals uniform distribution of Si3N4 without clustering.
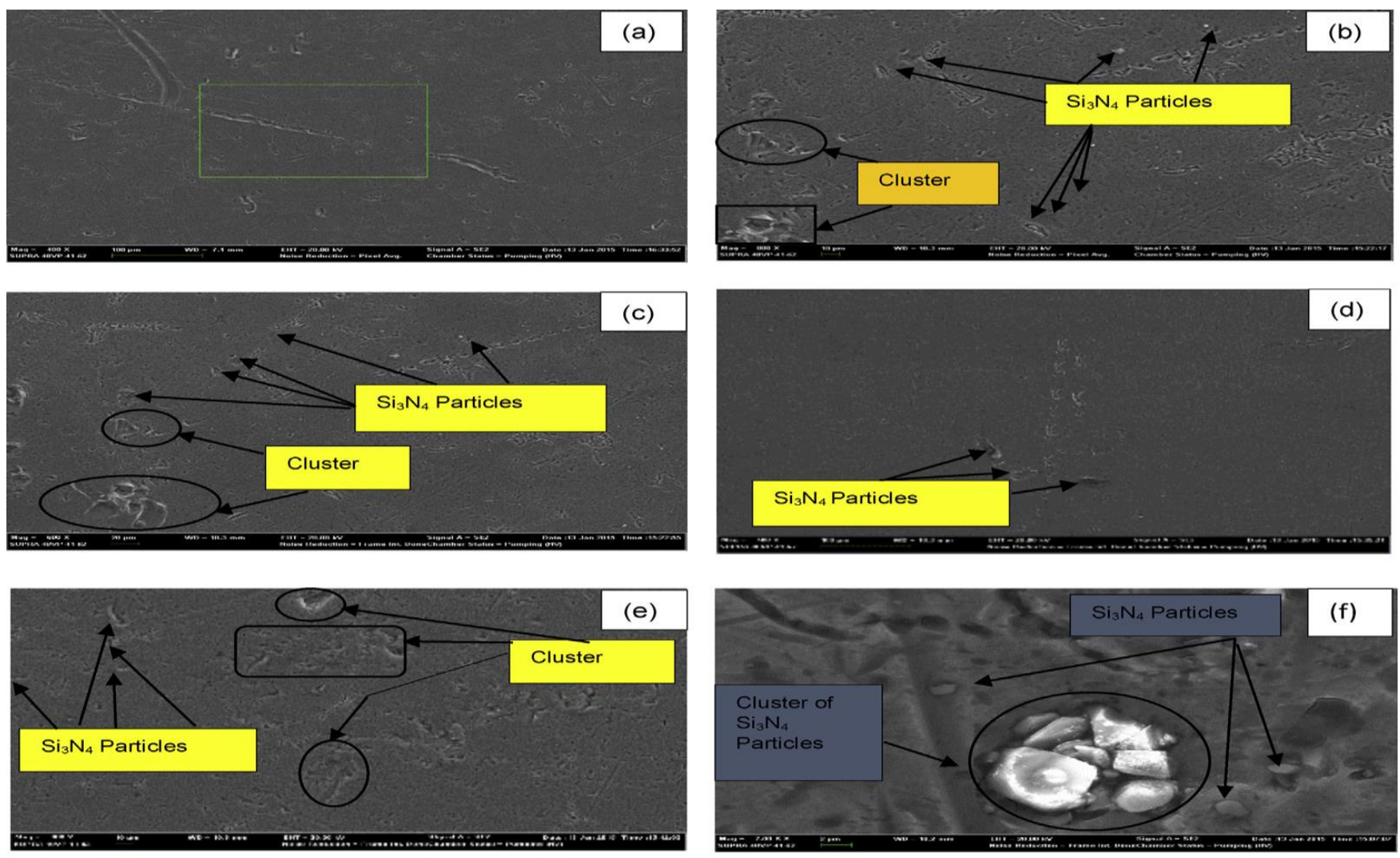

shows rich interfaces between matrix and reinforcement. Microstructure images by Sharma et al. [50] reported that, there were a uniform dispersion of Si3N4 and nano graphite particles in AA6061 alloy while the composite is fabricated via stir casting route. Amigo et al. [51]

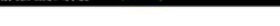

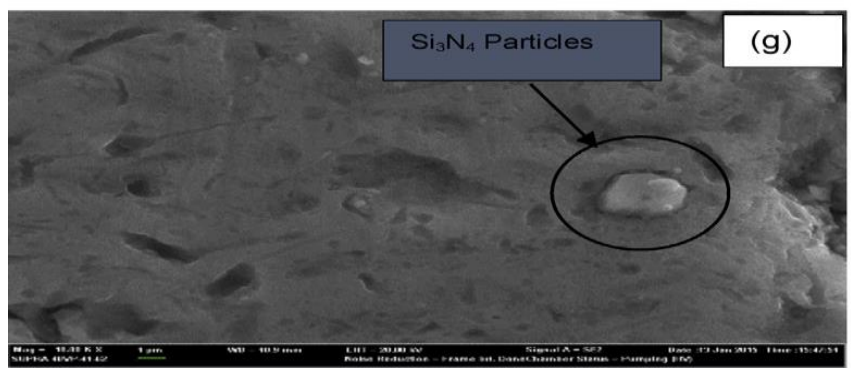

Fig.4: "SEM Photo micrographs of cast AA6082-Si3N4 AMCs: (a) 0 wt \% Si3N4, (b) 3 wt \% Si3N4, (c) 6 wt\% Si3N4, (d) 9 wt\% Si3N4, (e) 12 wt\% Si3N4, (f) 3 wt\% Si3N4 and (g) 12 wt\% Si3N4" [49].

\section{Mechanical Properties}

This section is focused on effect of the Si3N4 introduction in Al matrix for hardness and tensile strength.

\section{C- 1 Hardness}

Arik [39] performed hardness test for Al/10wt\% Si3N4 and observed that the hardness of mechanical milled composite samples is greater than the conventional mixed composite samples (coarser grain distribution) due to homogeneity of the mixture and fine size particle distribution that helps to grow the hardness with the sintering temperature and it reached to its maximum value at $660^{\circ} \mathrm{C}$ sintering temperature. After this temperature hardness gets decreased may be due to fractional melting of the composite. Diffusion at high temperature may be the reason for hardness increment up to a certain level of temperature. Shalby et al. [43] studied the hardness of Sic and Si3N4 reinforced A 359 alloy composite and found that the wt\% of reinforcement and aging time affects the micro- hardness of composite. Hardness increases in wavy form (I.e. with peaks and valleys) as aging time increases and after a certain value of aging time it get decreased . Hardness improves as the wt \% increases may be due to high hardness of the reinforcement. Fogognalo et al. $[52,53]$ investigated that the mechanical milling increases the hardness for composite (AA6061/5wt\% Si3N4) formed by powder metallurgy and it increases continuously with the milling time i.e. from 0 to 10 hrs.

Published By:

Blue Eyes Intelligence Engineering

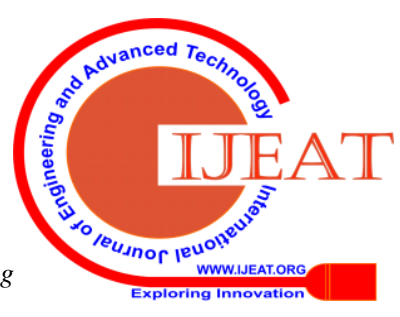


Although the ductility or elongation decreases and become minimum at 4.5 hrs milling time thereafter it increases slightly with milling time. Ramesh et al. [40,54] observed the hardness of AA6061/Si3N4 composite formed by stir casting method improved by $42.23 \%$ due to increase in $\mathrm{wt} \%$ (0 to $10 \mathrm{wt} \%$ ) of reinforcement i.e hard silicon nitride coated with
NI-P. This rise in hardness may be attributed to hard ceramic particle which resist the indentation along with the differences in thermal expansion coefficient between the phases (matrix \& reinforcement).

Table.3: Effect of change in wt \% of the reinforcement on hardness [56,57].

\begin{tabular}{|l|l|l|l|l|}
\hline \multirow{2}{*}{$\begin{array}{l}\text { Reinforcement } \\
\text { wt\%) }\end{array}$} & \multicolumn{1}{|c|}{$\begin{array}{c}\text { AA6082/ball milled (Gr+Si3N4) } \\
\text { (VHN) }\end{array}$} & $\begin{array}{l}\text { Macro-hardness } \\
\text { (BHN) }\end{array}$ & Micro-hardness (VHN) & $\begin{array}{l}\text { Macro-hardnes } \\
\text { s (BHN) }\end{array}$ \\
\cline { 2 - 5 } & 49.50 & 31.60 & 49.50 & 31.60 \\
\hline 0 & 72.00 & 40.00 & 82.00 & 48.00 \\
\hline 6 & 76.00 & 43.00 & 86.00 & 51.50 \\
\hline 9 & 81.00 & 47.00 & 91.00 & 55.00 \\
\hline 12 & 84.00 & 50.50 & 93.50 & 58.00 \\
\hline
\end{tabular}

Sharma et al. [50] tested \& found the Al6061/ (n-Gr/Si3N4) hybrid composite's micro hardness improved with wt $\%$ of reinforcing phase and the reason behind this improvement is use of hard reinforcing material. Amigo et al. [51] reported that composite is more favorable for aging to increase its hardness than unreinforced alloy and also composite takes less aging time for hardness improvement. He also reported that $15 \mathrm{wt} \%$ of Si3N4 gives highest hardness. Sharma et al. $[55,56,57]$ investigated micro and macro-hardness of the final composite (as in Table.3) and found gathering of hard ceramic into matrix hinders the plastic deformation and give rise to the hardness.

Keshavamurthy et al. [58] revealed the influence of ice, water and air quenching medium on the micro-hardness of AA6061/Si3N4 composites and found that the all quenching medium give a rise in hardness and \% increment is 37, 18 and $11 \%$ for ice, water and air medium respectively. Ambigai et al. [59] observed that the highest hardness is achieved with hybrid composite $\mathrm{Al} /(\mathrm{Gr}+\mathrm{Si} 3 \mathrm{~N} 4)$ which is $91.3 \mathrm{HV}$ after that composite (Al/nano-Si3N4) and at last with composite reinforced by graphite( $\mathrm{Al} / \mathrm{Gr}$ ) having values $78.5 \mathrm{HV}$ and 74.6 HV respectively. Accumulation of hard reinforcement my be cause behind this hardness rise . Sharma et al. [60] derived that the better spreading due to ball milling of hard particles also influences to the micro \& macro hardness of the Al hybrid composite, as the composition taken by them i.e $\mathrm{Al} / \mathrm{ball}-\mathrm{milled}$ (B4C/Si3N4). They reported increment in hardness as rise in $\mathrm{wt} \%$ of reinforcement.

\section{C- 2 Tensile Behavior}

Amigo et al. [51] developed extruded AA6061/Si3N4 (0, 5, and $15 \mathrm{wt} \%$ ) composites by powder metallurgy route and investigated the ultimate tensile strength or simply tensile strength (TS) and yield tensile strength or simply yield strength(YS) for hot extruded and T6 heat treated hot extruded composites and on the basis of mechanical property enhancement, it is found that the T6 treatment has better advantages over extruded composite. as shown in Table.4. It was also reported that the mechanical property depends more on particle distribution of reinforcement rather than vol. fraction. T6 treatment improves the strength and ductility of the low wt\% composite ( $5 w t \%$ Si3N4) which may be due to lower clustering and uniform distribution of precipitates.

Table.4: Effect of variation in wt\% of silicon nitride on mechanical properties of as hot extruded and T6 treated composite[51].

\begin{tabular}{|c|c|c|c|c|c|c|}
\hline \multirow[t]{2}{*}{$\begin{array}{l}\text { Wt\% of } \\
\text { reinforcement }\end{array}$} & \multicolumn{3}{|c|}{ As Hot Extruded Composit } & \multicolumn{3}{|c|}{$\begin{array}{l}\text { T6 Treated Composite } \\
\text { (after hot extruded) }\end{array}$} \\
\hline & $\begin{array}{l}\text { TS } \\
\text { (MPa) }\end{array}$ & $\begin{array}{l}\text { S 0.2\% } \\
\text { (MPa }\end{array}$ & $\mathrm{E}(\%)$ & $\begin{array}{l}\text { TS } \\
\text { (MPa) }\end{array}$ & $\begin{array}{r}\mathrm{S} 0.2 \% \\
(\mathrm{MPa})\end{array}$ & $(\%)$ \\
\hline 0 & 193 & 103 & 31.2 & 306 & 181 & 11.1 \\
\hline 5 & 215 & 98 & 16.3 & 351 & 230 & 11.5 \\
\hline 10 & 217 & 114 & 14.4 & 321 & 216 & 8 \\
\hline 15 & 197 & 110 & 6.6 & 319 & 212 & 5.7 \\
\hline
\end{tabular}

Fogognalo et al. [52] investigated that the mechanical milling offers heavy impact on the mechanical characteristics of the composite (AA6061/5 wt\% Si3N4). They reported increased tensile strength and increased directly with respect to milling time (from 0 to $10 \mathrm{hrs}$ ) but elongation rate decreases as milling time increased and reached to its minimum after 4.5 hrs of milling. Ramesh et al. [40,54] observed that increasing in $\mathrm{wt} \%$ silicon nitride coated by $\mathrm{Ni}-\mathrm{P}$ affects the tensile strength of composite and it is improving as displayed in fig.5. Findings of Mabuchi et al. [61] is whiskers offer high tensile strength over particulate reinforcement for the composite AA6061/Si3N4. This may be due to the more uniform distribution of the reinforcement. Figure 6 is taken from research article of XIU et al. [45], fig.6(a) reveals that there is decrement in flexural or bending strength with incremental change in volume percentage of silicon nitride for heat treated and casted samples too

Published By:

Blue Eyes Intelligence Engineering

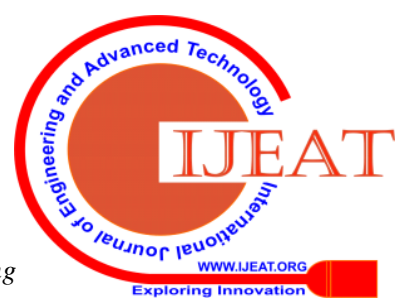




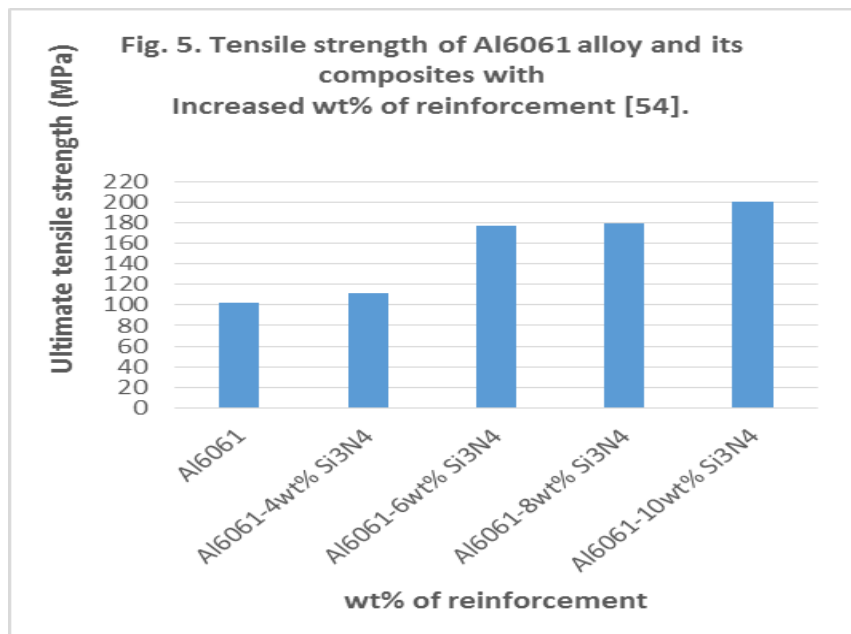

It is also concluded from the same fig that bending strength increased in high amount if composite is heat treated for a particular volume fraction. Fig.6 (b) shows the variation of bending modulus and depicts that it increased in small amount with the increment in volume fraction of reinforcement for both casted and heat treated samples. It is also concluded from the same fig. that a little increment has taken place possibly due to precipitation strengthening phenomenon caused by heat treatment.

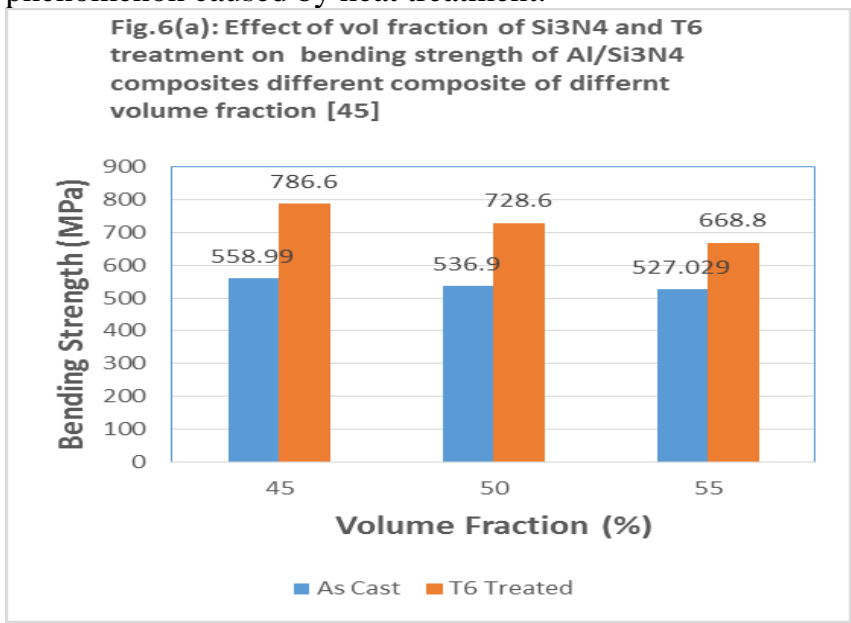

Fig.6(b): Effect of vol fraction of Si3N4 and T6 treatment on bending modulud of $\mathrm{Al} / \mathrm{Si} 3 \mathrm{~N} 4$ composites different composite of differnt volume fraction [45]
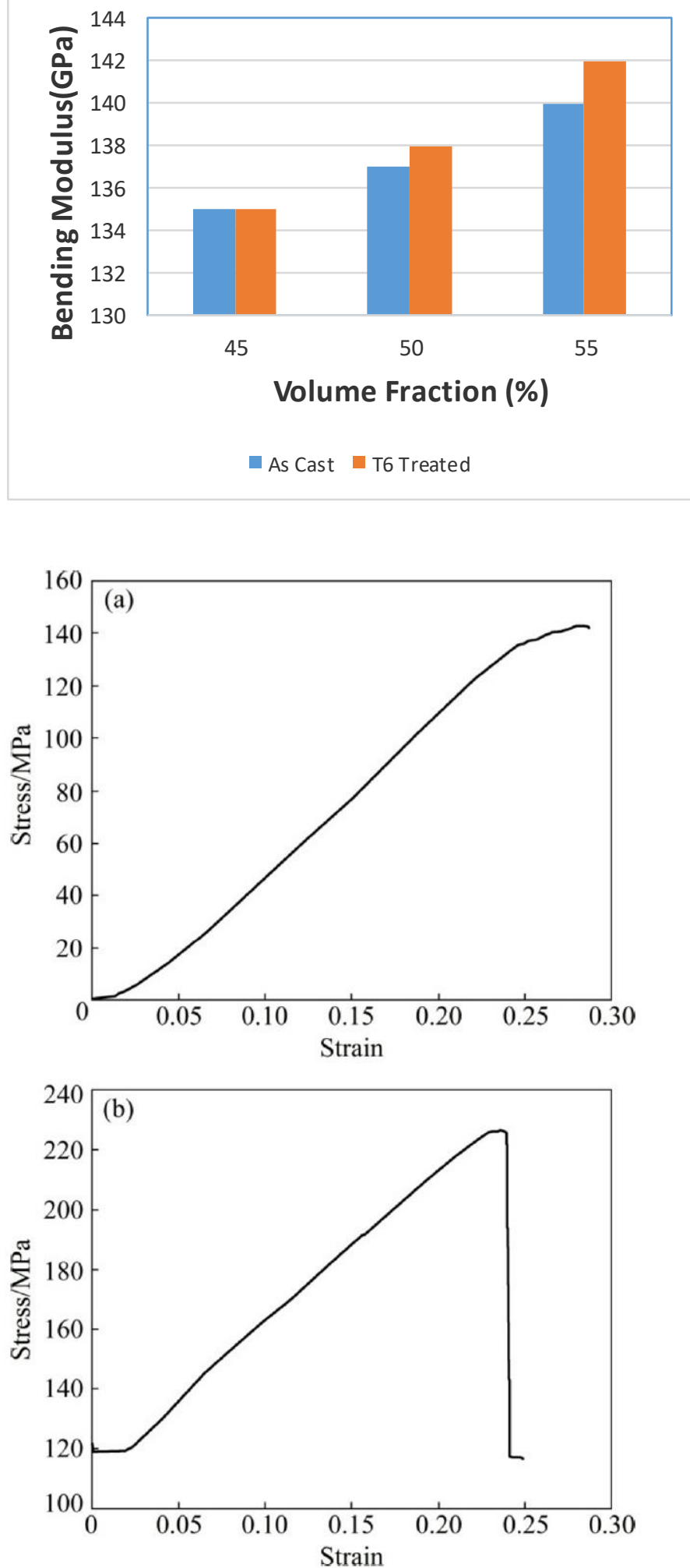

Fig.7. Tensile strength for (a) Al/Si3N4 composite and (b) Al/Gr-Si3N4 hybrid composite [59] 
Stress-strain diagram after performing tensile test by $\mathrm{R}$. Ambigai and S. Prabhu [59] shown in fig.7 (a,b) the curve shows the variation of stress with respect to change in strain for composite and hybrid composite. It contains elastic zone, yield plateau, strain hardening phenomenon, a continuous increment in stress with respect to strain till it reaches to its ultimate point and drop of stress until fracture occurs. From the fig it found that the tensile strength (ultimate strength) improves due to hybridization and it is improved by $58 \%$ [142.8 MPa for (a) to 226.3 MPa for (b) ] while there is a little decrement in ductility.

P. Sharma et al. [57] reported that with the incremental change of Si3N4 (0 to $12 \%$ ) particle in AA6082 matrix tensile strength improved by 25\% (from $161.5 \mathrm{MPa}$ to 201 $\mathrm{MPa}$ ) while ductility decayed by $51 \%$ (from 8.7 to 4.3 ).

\section{Tribological Properties}

Influence of silicon nitride as a reinforcement on the wear behavior like wear rate and coefficient of friction (COF) of aluminium composite is discussed herein this section. AMMCs have found different engineering applications where high wear and friction resistance are much desirable property for enhancing the life of component. It is highly necessary to minimize the wear loss whenever surface to surface contact is there [64]. Many researchers have put their efforts continuously to overcome this wear loss and investigating and optimizing dominating parameters for wear phenomenon for example load, sliding velocity, sliding distance etc. [65]. Sharma et al. [50] have worked for optimization of different wear parameters like load, sliding distance, sliding velocity for dry sliding wear response of the Al6061/(Si3N4+ n-Gr) hybrid composites using "response surface methodology (RSM) and genetic algorithm(GA)". It is confirmed from RSM plot that to minimize the wear loss the optimized condition is" high wt $\%$ of reinforcement, low sliding speed, low sliding distance and high load". SEM images of the worn surfaces confirms the mechanism of the wear for optimized condition and that was "abrasive, adhesive and fretting wear mechanism". Keshavamurthy et al. [58] developed Al6061-10wt\%Si3N4 composite by stir casting route and measured $\mathrm{COF}$ and rate of wear for casted and hot forged alloy and reinforced samples on the pin-on-disc wear tester under certain condition of loading and speed. They found $20 \%$ \& $25 \%$ reduction in COF for casted and forged sample rspectively.. The fall in COF with addition of Si3N4 may be attributed to anti-frictional nature of reinforced particles. It is also found that the heat treatment affects to COF for both cast and forged systems and the heat treated forged composite has higher COF as compare to cast alloy and its composites.

Ambigai et al. [59] investigated the wear rate for $\mathrm{Al} / \mathrm{Gr}$ and $\mathrm{Al} /$ nano-Si3N4 composites and Al/Gr-Si3N4 hybrid composites and found that it is directly varies with respect to applies load and this may be due to large area in contact with increment in the load and wear rate goes increases. Furthermore it is also derived that the $\mathrm{Al}$ with $\mathrm{Gr}$ gives lowest value of wear rate and COF that may be due to the fact that Gr has better solid lubrication characteristics hence it forms a tribo-layer between the contacting surfaces.. Radhika et al. [66] reported that the wear rate increases with applied load when performed wear test on "homogeneous and functionally graded LM25 aluminium (Al) reinforced with silicon nitride $(10 \mathrm{wt} \%, 40 \mu \mathrm{m})$ particles through liquid metallurgy and centrifugal casting". This increment in wear rate may be due to more surface area in contact and get decreased with rotating speed of rubber wheel may be due to entrenchment of sand particles. Ramesh et al. [67,68] studied that COF of Al6061/(different wt\% of Si3N4) composite decreases with incremental change in weight percentage of the reinforcement and load while with sliding speed it get increased. Formation of tribochemical layer is the cause behind low COF with incremental load also it is concluded that load and sliding speed directly affects to wear rate and it decreased non linearly with increment in reinforcement and load. Sharma et al. [55,69] investigated for Al6082-(Si3N4+Gr) composites that the wear rate directly varies with load and sliding distance while decreases with increased weight fraction of reinforcement and sliding speed. The ANOVA results depict that the sliding distance play a key wear affecting factor for composite.

\section{CONCLUDING REMARKS}

Achieving a noticeable property combination requires homogeneous dispersion of reinforcement in metal matrix. To obtain the homogeneous distribution processing parameters like temperature, time, speed in case of stir casting, stirrer geometry etc. play a very important role, so they must be taken into consideration during the processing of composite. Some preprocessing parameters like type of reinforcement, its shape and size are very important. From the literature it is found that the stir casting is widely used method to fabricate composite and hybrid composite due to its simplicity, and cost effectiveness although agglomeration or clustering of reinforcement is the major issues with this method. However some precaution for avoiding impurities in $\mathrm{Al} \&$ reinforcement and additional effort like preheating of reinforcing particles, addition of some wettability agent, degasing tablets etc. may reduce the chances of agglomeration, porosity and wettability problem. Powder metallurgy method may be a good alternative of stir casting since with this method it is easy to achieve the homogeneous dispersion and sufficient wettability. It is also found that heat treatment and thermo mechanical treatment have the potential to remove casting defects hence these two treatment may be frequently used in practice to get the better output. Si3N4 offers excellent property combinations for example high mechanical strength, good wear and corrosion resistance, high chemical and thermal stability at low and high temperature. From the study it is found that Si3N4 is feasible to use as reinforcement in aluminium matrix and offers good mechanical, structural and wear properties. From the literature, it is noted that the Si3N4 is suitable for high thermal and wear resistant application. From the study of current research it is confirmed that the Si3N4 is a potential candidate for reinforcing $\mathrm{Al}$ matrix, but very less work has been carried out for developing Si3N4 based hybrid aluminium metal matrix composite. So this may be a potential area to work for future prospects. For hybridization eco- friendly and cost effective materials like agricultural or industrial waste e.g. RHA (rice husk ash) \& FA (fly ash) may be used.

Very few work has communicated on the fracture behavior of the Si3N4 based Al composites. Hence a comprehensive study may be proposed to analyze the fracture behavior, its mechanics. 


\section{REFERENCES}

1. Srivatsan TS, Ibrahim IA, Mohamed FA, Lavernia EJ (1991) Processing techniques for particulate reinforced metal aluminum matrix composites. J Mater Sci 26:5965-5978

2. Shukla M, Dhakad SK, Agarwal P, Pradhan MK (2018) Characteristic behaviour of aluminium metal matrix composites: A review. Mater Today Proc 5:5830-5836

3. Bodunrin MO, Alaneme KK, Chown LH (2015) Aluminium matrix hybrid composites A review of reinforcement philosophies; Mechanical, corrosion and tribological characteristic. J Mater Res Technol 4:434-445

4. Miracle, Dan (2005) Metal Matrix composites - From Science to Technological Significance. Composites Science and Technology 65:2526-2540

5. Sinclair I, Gregson PJ (1997) Structural performance of discontinuous metal matrix composites. Mater Sci Technol 3:709-26

6. Rahman JF, Yunus M, Yezdani TMT (2012) Charting of a strategy for the application of aluminium metal matrix Composites for Different Engineering Service Requirements. Int J Mod Eng Res 2:1408-1413

7. Sahu PS, Banchhor R (2017) Effect of different reinforcement on mechanical properties of aluminium metal matrix composites. Res J Eng Sci 6:39-45

8. Mortensen A, Llorca J (2010) Metal Matrix Composites. Annu Rev Mater Res 40:243-270

9. Jain P, Soni S, Baredar P (2014) Review on machining of aluminium metal matrix composites. Mater Sci Res India. 11:114-120

10. Ramnath BV, Elanchezhian C, Atreya TSA, Vignesh V (2014) Aluminum metal matrix composites - a review. Rev Adv Mater Sci 38:55-60

11. Rino JJ, Chandramohan D, Sucitharan KS (2012) An overview on development of aluminium metal matrix composites with hybrid reinforcement matrix. 1:196-203

12. Milos K, Juric I, Skorput P (2011) Aluminium based composite materials in construction of transport means. Sci Traffic Transp 23:87-96

13. Ma Kaka , Enrique JL, Julie MS (2017) Particulate reinforced aluminum alloy matrix composites-a review on the effect of micro constituents. Rev Adv Mater Sci 48:91-104

14. Sharma R, S.J. P, Kakkar K, Kamboj K, Sharma P (2017) A Review of the aluminium metal matrix composite and its properties. IRJET 04:832-842

15. Shivasankaran N (2017) Aluminium metal matrix composites-A Review. TASTONLINE 01:

16. A. Macke, Schultz BF, Rohatgi P (2012) Metal matrix composites offer the automotive industry an opportunity to reduce vehicle weight, improve performance. Adv Mater Process 170:19-2

17. Chawla KK (1997) Composite Materials - Science and Engineering. 2nd Ed Springer-Verlag New York 102.

18. Chawla KK, Metzger M (1972) J Mater Sci 7, 34

19. Arsenault RJ, Shi N (1986) Mater Sci Eng 81, 175

20. Panwar N , Chauhan A (2018) Fabrication methods of particulate reinforced Aluminium metal matrix composite-A review. Mater Today Proc 5:5933-5939

21. Vijaya Bhaskar K, Sundarrajan S, Subba Rao B, Ravindra K (2018) Effect of reinforcement and wear parameters on dry sliding wear of aluminum composites-A review. Mater Today Proc 5:5891-5900

22. Yashpal, Sumankant, Jawalkar CS, Verma AS, Suri NM (2017) Fabrication of Aluminium Metal Matrix Composites with Particulate Reinforcement A Review. Mater Today Proc 4:2927-2936

23. Alaneme KK, Aluko AO (2012) Fracture toughness (K1C) and tensile properties of as-cast and age-hardened aluminium (6063) -silicon carbide particulate composites. Sci Iran 19(4):992-996

24. Alaneme KK, Bodunrin MO (2013) Mechanical behaviour of alumina reinforced AA 6063 metal matrix composites developed by two step stir casting process. Acta Tech Corvininesis - Bull Eng 6(3):105-110

25. Singh J, Chauhan A (2016) Characterization of hybrid aluminum matrix composites for advanced applications - A review. J Mater Res Technol 5:159-169

26. Alaneme KK, Aluko AO (2012) Production and age-hardening behaviour of borax premixed SiC reinforced Al-Mg-Si alloy composites developed by double stir casting technique. West Indian J Eng 34(1-2):80-5

27. Hashim J, Looney L, Hashmi MSJ (1999) Metal matrix composites: production by the stir casting method. Journal of materials processing technology Elsevier BV Netherlands. Volume 92-93:1-7
28. Zhou W, Xu ZM (1997) Casting of SiC reinforced metal matrix composites. Journal of material processing technology Elsevier BV Netherlands Volume63:358-363

29. Michael J, Kumar JS (2018) Fabrication and Characterization of hybrid aluminium metal matrix composite. Int Res J Eng Technol 05(06)

30. Sharma P, Khanduja D, Sharma (2015) 4th International Conference on Material Processing and Characterization. 14-15 March GRIET Hyderabad India Mater Today Proc Elsevier (in press)

31. Han IS, Seo DW, Kim SY, Hong KS, Guahk KH, Lee KS (2008) J Eur Ceram Soc 28:1057-1063

32. Xiu ZY, Chen GQ, Liu YM, Yang WS, Wu GH (2009) Trans Non ferr Met Soc China 19:373-377

33. Zhu X, Zhou Y, Hirao K (2004) Effect of sintering additive composition on the processing and thermal conductivity of sintered reaction-bonded Si3N4. J Am Ceram Soc 87(7):1398-1400

34. Lange FF (1973) Relation between strength, fracture energy, and microstructure of hot-Pressed (Si3N4). J Am Ceram Soc 56:518-522

35. Kishore Kumar PR, Manikandan VN, Deepak Raj P, Sridharan M(2016) Characterization of magnetron sputtered Si3N4 thin films deposited on Aluminum alloy substrates. Mater Today Proc 3:1536-1540

36. Tuchinskiy L, Veksler E, Loutfy R, Williams M (2000) Tribological characteristics of Si3N4-based self-lubricating materials. Tribol Trans 43:603-610

37. Bocanegra-Bernal MH, Matovic B (2010) Mechanical properties of silicon nitride-based ceramics and its use in structural applications at high temperatures. Mater Sci Eng A 527:1314-1338

38. Carrasquero E, Bellosi A, Staia MH(2005) Characterization and wear behavior of modified silicon nitride. Int J Refract Met Hard Mater 23:391-397

39. Arik H (2008) Effect of mechanical alloying process on mechanical properties of alpha-Si3N4 reinforced aluminum-based composite materials. Mater Des 29:1856-1861

40. Ramesh CS, Keshavamurthy R, Madhusudhan J (2014) Fatigue behavior of Ni-P coated Si3N4 reinforced Al6061 composites. Procedia Mater Sci 6:1444-1454

41. Sharma S, Khanduja P, Sharma D(2015) Production of AA6082Si3N4/Gr hybrid composite by a novel process and evaluation of its physical properties. I-Manager's J Mater Sci 2:13-20

42. Bai X, Huang C, Wang J, Zou B, Liu H (2015) Fabrication and characterization of Si3N4 reinforced $\mathrm{Al} 2 \mathrm{O} 3$-based ceramic too materials. Ceram Int 41:12798-12804

43. Shalaby EAM, Churyumov AY, Solonin AN, Lotfy A (2016) Preparation and characterization of hybrid A359/(SiC+Si3N4) composites synthesized by stir/squeeze casting techniques. Mater Sci Eng A 674:18-24

44. Senel MC, Gurbuz M, Koc E (2017) Fabrication and Characterization of SiC and Si3N4 Reinforced Aluminum Matrix Composites. Univers J Mater Sci 5:95-101

45. Xiu Zy, Chen Gq, Wu Gh, Yang Ws, Liu Ym (2011) Effect of volume fraction on microstructure and mechanical properties of Si3N4/Al composites. Trans of Nonferr Metals Soc of China 21 285-289

46. Fayomi J, Popoola API, Oladijo OP, Popoola OM, Fayomi OSI (2019) Experimental study of ZrB2-Si3N4 on the microstructure, mechanical and electrical properties of high grade AA8011 metal matrix composites. J of Alloys and Compounds 790:610-615

47. Inegbenebor AO, Bolu CA, Babalola PO, Inegbenebor AI, Fayomi OSI (2016) aluminum silicon carbide particulate metal matrix composite development via stir casting processing. Springer Science Business Media Dordrecht JrnlID 12633 ArtID 9451

48. Popoola API, Pityana SL, Popoola OM (2011) Microstructure and corrosion properties of $\mathrm{Al}(\mathrm{Ni} / \mathrm{TiB} 2)$ intermetallic matrix composite coatings. J South Afr Inst Min Metall 111: 345 SA ISSN 0038e223X/3.00

49. Sharma P, Sharma S, Khanduja D (2015) Production and some properties of Si3N4 reinforced aluminium alloy composites. Journal of Asian Ceramic Societies

50. Sharma N, Khanna R, Singh G, Kumar V (2016) Fabrication of 6061 aluminum alloy reinforced with Si3N4 / n-Gr and its wear performance optimization using integrated RSM-GA. Part Sci Technol 6351

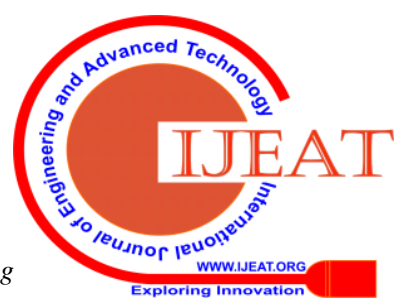


51. Amigo V, Ortiz JL, Salvador MD (2000) Microstructure and mechanical behavior of 6061Al reinforced with silicon nitride particles, processed by powder metallurgy. Scr Mater 42:383-388

52. Fogagnolo JB, Ruiz-Navas EM, Robert MH, Torralba JM (2002) $6061 \mathrm{Al}$ reinforced with silicon nitride particles processed by mechanical milling. Scr Mater 47:243-248

53. Fogagnolo JB, Robert MH, Torralba JM (2003) The effects of mechanical alloying on the extrusion process of AA 6061 alloy reinforced with Si3N4. J Brazilian Soc Mech Sci Eng 1-11

54. Ramesh CS, Keshavamurthy R, Channabasappa BH, Ahmed A (2009) Microstructure and mechanical properties of Ni-P coated Si3N4 reinforced Al6061 composites. Mater Sci Eng A 502:99-106

55. Sharma P, Sharma S, Khanduja D (2015) Parametric Study of Dry Sliding Wear Behavior of Hybrid Metal Matrix Composite Produced by a Novel Process. Metall Mater Trans A 46:3260-3270

56. Sharma P, Sharma S, Khanduja D (2016) Production and characterization of AA6082-(Si3N4 + Gr) stir cast hybrid composites. Part Sci Technol 6351:1-8

57. Sharma P, Sharma S, Khanduja D (2015) Production and some properties of Si3N4 reinforced aluminium alloy composites. J Asian Ceram Soc 3:352-359

58. Keshavamurthy R, Sudhan JM, Gowda N, Krishna RA (2016) Effect of thermo-mechanical processing and heat treatment on the tribological characteristics of Al Based MMC's. IOP Conf Ser Mater Sci Eng 149

59. Ambigai R, Prabhu S (2017) Optimization of friction and wear behaviour of $\mathrm{Al}-\mathrm{Si} 3 \mathrm{~N} 4$ nano composite and $\mathrm{Al}-\mathrm{Gr}-\mathrm{Si} 3 \mathrm{~N} 4$ hybrid composite under dry sliding conditions. Trans Nonferrous Met Soc China English Ed. 27:986-997

60. Sharma P, Khanduja D, Sharma S (2014) Metallurgical and Mechanical Characterization of Al 6082-B4C/Si3N4 Hybrid Composite Manufactured by Combined Ball Milling and Stir Casting. Appl Mech Mater 592-594:484-488

61. Mabuchi TIM (1993) Production of superplastic aluminium composites reinforced with $\mathrm{Si} 3 \mathrm{~N} 4$ by powder metallurgy. 28:6582-6586

62. Wang X, Chen GQ, Yang WS, Hussain M, Wang CC, Wug H, Jiang $\mathrm{D} \mathrm{M}$, Effect of $\mathrm{Nd}$ content on microstructure and mechanical properties of Grf/Al composite. J Mat Science and Engg A

63. Wu GH, Sonh MH, Xiu ZY, Wang N, Yang WS (2009) Microstructure and properties of M40 carbon fibre reinforced Mg-Re-Zr alloy composites. Journal of Mat Science \& Tech 25(3): $423 \square 426$

64. Mistry JM, Gohil PP (2017) An overview of diversified reinforcement on aluminum metal matrix composites: Tribological aspects. Proc Inst Mech Eng Part J J Eng Tribol 231:1-23

65. Ganesh R, Subbiah R, Chandrasekaran K (2015) Dry sliding wear behavior of powder metallurgy luminium Matrix composite. Mater Today Proc 2:1441-1449

66. Radhika N (2016) Comparison of the mechanical and wear behaviour of aluminium alloy with homogeneous and functionally graded silicon nitride composites. Sci Eng Compos Mater 1-11

67. Ramesh CS, Keshavamurthy R, Channabasappa BH, Pramod S (2010) Friction and wear behavior of $\mathrm{Ni}-\mathrm{P}$ coated Si3N4 reinforced Al6061 composites. Trib Int 43:623-634

68. Ramesh CS, Keshavamurthy R, Pramod S, Koppad PG (2011) Abrasive wear behavior of $\mathrm{Ni}$ - P coated Si3N4 reinforced Al6061 composites. J Mater Process Tech 211:1423-1431

69. Sharma P, Khanduja D, Sharma S (2015) Parametric Study of Dry Sliding Wear of aluminium metal matrix composites by response surface methodology. Mater Today Proc 2:2687-2697

\section{AUTHOR PROFILE}

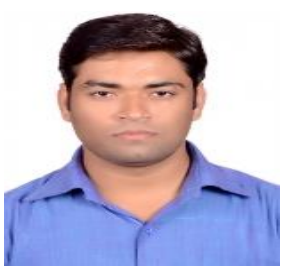

Ranjeet Kumar Arya is currently pursuing $\mathrm{PhD}$ in Mechanical Engineering Department at Maulana Azad National Institute of Technology (M.A.N.I.T), Bhopal, Madhya Pradesh India. He graduated from Rajiv Gandhi Proudhyogiki Vishwavidhyalaya, Bhopal with Bachelor of Engineering-Mechanical Engineering in 2007. He completed his Masters of Technology in Engineering Materials from M.A.N.I.T in 2010. Presently he is working as an Assistant Professor in the Department of Mechanical Engineering at Corporate Institute of Science \& Technology, Bhopal, India. His research interest includes materials synthesis and characterization with emphasis on the mechanical and wear performance of Aluminium metal matrix composites.

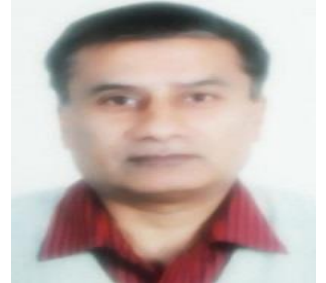

Dr. Amit Telang is currently working as an Assistant Professor in the Department of Mechanical Engineering at Maulana Azad National Institute of Technology (M.A.N.I.T), Bhopal, Madhya Pradesh, India. He has 26 years of vast teaching, research and industrial experience. He received his Doctoral and Masters Degree from the same institute. He has published one book and has authored or co-authored over 40 published articles. His research interests are in the area of Tribology and Composite Materials. He is a member of Institution of Engineers and ISTE. 